\title{
La figura de los Hacedores de Apoyo en la co-formación de referentes de prácticas socioculturales.
}

\author{
Bianco Dubini, Germán
}

Universidad de Buenos Aires, Argentina germanbdubini@yahoo.com.ar

\section{Resumen}

En el marco de Cultura Imaginada (actividad que reconoce el accionar de colectivos culturales argentinos), los/as Hacedor/a de Apoyo (referentes del ámbito académico $\mathrm{y} / \mathrm{o}$ de prácticas, con experiencia territorial, trayectoria temática y capacidad docente), coordinan espacios temáticos que apuntan a optimizar el trabajo territorial de las prácticas participantes. No obstante compartir conceptual, metodológica e ideológicamente una perspectiva pedagógica participativa, se han identificado contradicciones en el actuar de algunos/as Hacedores de Apoyo vinculadas a la connivencia con formas clásicas de enseñanzaaprendizaje. Retomando los aportes analíticos brindados por las matrices constitutivas de la Trama Cultural, se expondrán algunas características que adquieren los formatos pedagógicos para repensar propuestas que, desde la construcción colectiva de conocimientos y métodos, sostengan reales co-formaciones entre pares.

Palabras clave: hacedores de apoyo; co-formación; trama cultural; prácticas socioculturales de grupos independientes; poder sobre los propios actos;

\section{Abstract}

Within the framework of Cultura Imaginada (activity that recognizes the actions of Argentine cultural collectives), the Support Maker (referring to the academic and / or internship field, with territorial experience, thematic trajectory and teaching capacity), coordinates spaces thematic ones that aim to optimize the territorial work of the participating practices. Despite the conceptual, methodological and ideological sharing of a participatory pedagogical perspective, contradictions have been identified in the actions of some Support Makers linked to connivance with classic forms of teaching and learning. Returning to the analytical contributions provided by the constitutive matrices of the Cultural Plot, some characteristics acquired by the pedagogical formats will be exposed to rethink proposals that, from the collective construction of knowledge and methods, sustain real coformations between peers

Keywords: makers of support; coformation; cultural plot; socio-cultural practices of independent groups; power over their own acts; 


\section{INTRODUCCIÓN}

"Cultura Imaginada" es una iniciativa del Programa de Cultura del Consejo Federal de Inversiones ${ }^{1}$ (Argentina) que, desde 2016 y con el apoyo de las áreas de cultura provinciales, reconoce, acompaña, fortalece y difunde la tarea producida por hacedores culturales pertenecientes a grupos e instituciones independientes de todo el país que, desde las disciplinas artísticas y la gestión $y$, con distintos métodos didáctico pedagógicos, trabajan en campos vinculados con las identidades, la diversidad, el patrimonio inmaterial, el rescate y salvaguarda de saberes, el cuidado del entorno ambiental, el hábitat, la producción económica, el trabajo cooperativo, la participación comunitaria, la educación artística, el derecho al juego, la promoción de la lectura y escritura, la salud, la discapacidad, la formación de públicos, la violencia de género y otras modalidades de maltrato y exclusión. ${ }^{2}$
Es una práctica para las prácticas, en la medida que contribuye a fortalecer acciones colectivas creadoras de sociedades cada vez más autónomas (en tanto construcción colectiva desde la reciprocidad) y libres, que cuestionan su pensamiento y haceres heredados a los fines de darse sus propios criterios para la formulación de de políticas culturales en particular, y de formas de vivir en general.

Que sea imaginada, no significa que quede en el plano de la fantasía. El estar anclada en el principio de realidad la hace viable. En esa realidad se van incorporando los aportes de otras prácticas que esgrimen otros haceres y renuevan el horizonte. $Y$ hacen pensable lo que antes era invisible, inexistente, improbable en función de las experiencias y saberes grupales disponibles. Así lo imposible ingresa en el campo del Hacer. La Cultura Imagi-

1. Se trata de una institución pública y autárquica, de alcance nacional con impronta federal. Es un organismo de y para las provincias en la medida que su presupuesto surge de un porcentaje de la coparticipación federal. La institución devuelve esos recursos económicos en acciones técnicas en distintas áreas, una de ellas Cultura.

2. Durante el 2019 se implementará la $4^{\text {a }}$ edición de Cultura Imaginada, bajo el lema "Exploratoria 2019 Región Nordeste" (provincias de Chaco, Corrientes, Formosa y Misiones). 
nada es también histórica, no predefinida. La orientan ideas, creencias, ideologías, pero ni en lo individual ni en colectivo hay un a priori. Aunque el Qué y el Para qué puedan ser más estables, el Cómo hace que lo cultural y su concreción está siempre en movimiento.

En publicaciones anteriores se ha detallado lo concerniente a los conceptos teórico-metodológicos que sustentan esta iniciativa; los alcances políticos (Bianco Dubini, 2017); las maneras de convocar y explorar territorialmente las prácticas socioculturales; la organización, fundamento, temas de abordaje y modalidad pedagógica desarrollada en los encuentros temáticos virtuales y presenciales de co-formación (Consejo Federal de Inversiones (CFI), 2017) y; las publicaciones (destacando lo más significativo de las prácticas seleccionadas y preseleccionadas y las recomendaciones planteadas por el equipo evaluador en tanto hacedores de apoyo) (CFI, 2016 y CFI, 2019).

En esta oportunidad, se explicitarán las dificultades que aún surgen de algunos/as Hacedores/as de
Apoyo al momento de coordinar de espacios temáticos que continúan pareciéndose más a una formación clásica que uno de co-formación tal como lo requiere Cultura Imaginada. En lugar de trabajar desde lo que genera cada práctica a los fines de abordarlas, cuestionarlas o aportarles colectivamente, muchos continúan trayendo como recurso didáctico solo su propia experiencia para volcarla en la práctica de otros $y$, desde la mirada pedagógica, la posición asumida es la de quien detenta el saber y el otro que toma las ideas, sugerencias y analiza en todo caso, como puede adaptarlas a su práctica. Lo cual convierte una tarea valiosa pero contradictoria en términos de una epistemología de la práctica y su correlato pedagógico (Gagneten, Tierno y Colombo, 2017)

Para poder comprender los aspectos que se resaltarán de estas dificultades, es necesario considerar por un lado, dos certezas fundantes: 1) la práctica funda la teoría, para que una vez constituida vuelva a fortalecer las prácticas;

2) la transformación será de peso y sostenible si es que se construye 
desde lo colectivo. Por otro lado, la necesidad dar cuenta de algunas acciones que son pilares en Cultura Imaginada.

\section{¿Qué significa un Encuentro?:} Hacer desde nosotros y con otros, para todos. Un ámbito colectivo de trabajo que alberga a los diferentes hacedores y sus prácticas territoriales, facilitando las condiciones para el desarrollo de aspectos como:

- La producción y circulación democrática de posibles innovaciones y nuevos conocimientos académicos y de oficios surgidos desde el terreno.

- La co-formación entre los distintos hacedores culturales. EI que fue formador en un espacio específico pasa a ser formado por esos mismos pares en otro momento a partir del intercambio cooperativo de experiencias, saberes y aprendizajes teóricos, pedagógicos y metodológicos.

- El fortalecimiento de las prácticas en términos de argumentación, planificación, registro y sistematización.

- La implementación de dinámicas lúdico-artísticas vinculadas a los temas de trabajo propuestos.
- La profundización de redes estratégicas entre prácticas de la propia región y del país que favorezcan el diseño e implementación conjunto de nuevas propuestas socioculturales;

- La identificación de las necesidades de estos grupos a fin de contribuir a satisfacerlas a través de distintos formatos de asistencia.

- El registro y evaluación de las actividades implementadas a los fines de explicitar aprendizajes concretos e identificar temas emergentes que sean abordados desde los conocimientos existentes en los diferentes grupos participantes y/o con el apoyo de otros agentes culturales invitados con trayectoria probada.

- El reconocimiento de contenidos y métodos surgidos de los intercambios de saberes y aprendizajes sistematizados de las experiencias de terreno aportados por los hacedores culturales protagonistas y los Hacedores de Apoyo convocados.

Los Encuentros son los ejes medulares de Cultura Imaginada, las vías para favorecer un entramado federal de prácticas culturales. En- 
contrarse para multiplicar, replicar, acompañar, vislumbrar nuevos espacios, nuevas alternativas y miradas. Son una herramienta para visibilizar la acción cultural regional, por los mismos actores que la desarrollan, que comparten el campo de trabajo, para fortalecerse y nutrirse recíprocamente de las experiencias que cada uno desarrolla, para establecer puntos en común y abrir el juego de esta urdimbre viva de la Argentina.

\section{¿Qué supone ser Hacedores}

Culturales?: creadores, gestadores, gestores, productores. Somos quienes trabajamos con nuestra cabeza, métodos, recorridos, manos y pasión. Disfrutamos de aprender del hacer propio, de ser formadores de nuestros pares y de ser formados por esos mismos pares. Los límites de qué es lo propio y qué deviene de los novedosos aportes de los otros hacedores, se hacen difusos para diluirse en una construcción colectiva que se ancla en un más bello trabajo territorial.

No es algo al azar nombrar a los Encuentros con el lema: "De los hacedores para los hacedores". Se trata de considerar a quienes llevamos a cabo prácticas culturales en los distintos territorios, como autores de acciones que buscan generar autonomía en quienes participan de ellas. Seres capaces de analizar su situación, reflexionar sobre ella para, a partir de los saberes con los que cuentan e incorporan críticamente, intervenir para fortalecer - modificar sus condiciones de existencia desde la perspectiva cultural. Los hacedores entonces son personas que cuestionan su herencia, para romper con aquellas ataduras que los pueden ligar a prácticas reproductivas y alienantes (Castoriadis, 1993), para poder pensar con otros, formas saludables y satisfactorias de vivir la vida (Dejours, 1990).

Y es así que desde distintas miradas compartidas, rompen la idea de competencia para desde la cooperación grupal y colectiva, formarse unos a otros. Por momentos enseñando a los otros sus métodos, didácticas, aprendizajes, por momentos recibiéndolos de ellos. No importa el nivel formal educativo. Los hacedores pueden haber aprendido en la universidad de la 
práctica, en la de las aulas o en ambas. Los hacedores aprenden del terreno, lo analizan, reflexionan, generar teoría y conceptos, diseñan procedimientos, técnicas, métodos, didácticas, pedagogías y vuelven a intervenir en el terreno con los nuevos saberes que han adquirido de la propia experiencia o de la de otros. No para convertirse en lo homogéneo, en la respuesta única, sino como apertura y adaptación crítica a la práctica que encarna.

Algunos hacedores/as en particular son propuestos/as como Hacedores de Apoyo para: conformar el equipo evaluador durante la convocatoria de las prácticas y la coordinación de espacios temáticos en los encuentros. Son referentes con trayectoria y experiencia de terreno y/o académica $y$, que nos acompañan en el abordaje de los temas programados en función de las prácticas participantes. El Hacedor de apoyo no le dice al otro lo que tiene que hacer, sino que comparte generosa y estratégicamente su práctica maestra, sus experiencias sistematizadas para ponerlas al servicio de sus pares.

\section{La Trama Cultural}

Afirma Gagneten (2008): "Es una herramienta de análisis que posee una estructura lógico - metodológica que permite procesar los elementos que dan cuenta de la presencia de los rasgos de cada matriz cultural en toda práctica sistematizada... Cada matriz, en tanto tipo ideal y en su existencia abstracta, define un modo de estar, creer, sentir, pensar y actuar que posee una coherencia interna. Las personas actuamos en nuestras prácticas portando siempre un entramado de rasgos de las matrices, una combinatoria particular, donde alguna de ellas prima sobre las otras".

Las matrices sufren modificaciones a raíz de las transformaciones de los procesos históricos y las relaciones de fuerza entre las clases sociales. Veamos sintéticamente cómo las distintas matrices atraviesan $Y$ actúan a la hora de constituirse como hacedores de apoyo.

\section{Matriz Ancestral}

La Pedagogía desde los Encuentros. 
- Retoma ese espacio sagrado de compartir lo realizado, el dicho hecho concreto (con obstáculos y dificultades y logros, alegrías y tristezas, caídas y levantadas), no lo que se dice que se va a hacer.

- Es el cruce de caminos al que llegan, como búsqueda o espontáneamente, quienes van generando horizontes en común: El encontrarse. $Y$ donde se ve reflejado cada uno en su producción pero sobre todo a la luz de las producciones del resto. Hay una dimensión real del alcance de cada práctica que surge desde el compartir.

- hay un Reconocimiento del trabajo de todos (en grupos y colectivos): aquí el conocimiento y el saber hacer están avalados por los pares o por la comunidad de pertenencia en tanto criterio de abstracción pero también de utilidad para el vivir (para qué sirve lo que hacemos). Ese juicio estético es el más valorado por quienes llevan a cabo una tarea. Un conocimiento y hacer que genera más vida (Dejours, 2003).

- Como lugar de cooperación, de ayuda, de acompañamiento, donde lo desigual (en formaciones, trayectorias vitales, experiencias, vivencias, títulos) se iguala a la hora de acceder a las historias de trabajo del resto. Allí no se guarda nada. Es brindarse. No hay mezquindades ni actitudes miserables. Es el deseo cierto de crecimiento profundo de toda práctica, para volver prácticas hermanas.

- Quienes parten "desde el pie" para construir conocimiento colectivo, no ya para una práctica, sino para todas. Retoman los conocimientos y contenidos culturales anclados en lo territorial, histórico, político, identitarios, desde las creencias, mitos, leyendas, ideologías valores, las expresiones simbólicas (música, danzas, pinturas, dibujos, juegos, formas de crianzas, preparación de comidas, diseños textiles a partir de elementos del propio entorno) y la creatividad. Este conocimiento es estratégico para el hacer pero también para que desde los vínculos saludables, lo epistemofílico pueda habilitar lo epistemológico.

\section{Matriz Dominante}

- La "llegada" al conocimiento institucionalmente formalizado, certificado, que brinda avales. Es decir, hay quienes detentan ese saber consagrado por las distintas instituciones certificadoras (en distintos "niveles" y 
categorías de saber). Desde los notables a los meramente reconocidos por el sistema educativos para avalar su condición, son esas personas quienes enseñan a los que "no saben" por lo que su función es guiarlos hacia un saber ya predefinido y consagrado. Los portadores de cultura preparan a los aculturados, sin analizar ni preguntarse por las desigualdades originarias en el acceso a la educación formalizada.

- Llegar a participar de ellas puede ser el salto al triunfo, a marcar agenda, a generar las políticas educativas desde los expertos. Entonces estar por fuera de este formato acerca más de la civilización a la barbarie, o desde la cultura a la no cultura. La existencia de "gente sin cultura", una de las falacias difundidas por los modelos de producción hegemónicos a partir de la auto-atribución de la potestad cultural que coindice justamente con los rasgos característicos de un grupo minúsculo dentro de las naciones hegemónicas.

- La educación es una pirámide en donde el pináculo lo habitan los expertos consagrados (a partir de un sistema de competitivo de concursos, acreditaciones. Una "carrera" educativa) y de allí para abajo: los títulos, especialistas, profesionales. En definitiva

- Acuerdan en algo a pesar de sus niveles diferentes: que quien no porta alguno de estos títulos, no tiene educación. La educación por tanto solo se obtiene en espacios formalizados para tal fin y con una currícula avalada por ministerios. En síntesis, en el campo de la enseñanza educativa, hay también representantes ganadores y perdedores. $Y$ eso se nota en las instituciones donde trabajan o son destinados.

- Este modelo posee varias negaciones. Por ejemplo:

- las condiciones de acceso incluso a ese saber hegemónico: los elegidos, los que se esfuerzan, los que se sacrifican. Así las condiciones de existencia no son consideradas, pues "llegar" es por méritos individuales.

- La existencia de otras formas de acumulación de saberes, prácticas, conceptos y de inclusión de lo afectivo. Estos son denostados, tildados de ignorante, poco científico, incomprobables. Al mismo tiempo, separa los contenidos conceptuales de las prácticas (o sea de los devenidos del hacer). 
- Mercantilización del saber: ligada a lo económico, quienes no hayan "hecho los deberes" les será difícil acceder a un "bien" como tantos otros, como lo es la educación.

- En esta línea de pensamiento, hay una variable limitada de pedagogías oficiales que aseguren esta ideología y que rechace a quienes no la pueden acatar.

\section{Matriz dependiente}

- Se da en los espacios temáticos que más allá de presentarse como de co-formación no hacen más que reproducir el modelo dominante educativo. En general en estos espacios quienes coordinan no se interiorizan en las prácticas previamente para conocerlas en profundidad (más allá de brindarles los materiales y sitios), pero tampoco las consultan en el marco del Encuentro. A lo sumo alguna mirada por arriba para ver "qué contenidos traerles". Es decir, aun de manera inconsciente, no artera, se busca "ayudar" a esa práctica a partir de metodologías, bibliografías y conceptos ya prefijados en el marco teórico del "co-formador" devenidos en general de autores extranjeros consagrados académicamente.
Conocimientos que aún con alegría y real interés, son vomitados en formatos de clases magistrales aun cuando se está fuera de las aulas.

- Puede decirse que reproducen "el mármol", el frío conocimiento, la rigidez, en general además generado por otros y no por el propio formador con algún grupo. En este sentido muchos se convierten en autorreferenciales, en lugar de usar esa referencia como comparación de prácticas. Este estilo muchas veces muestra un destello de vanidad, aparece más una búsqueda de lucimiento de quien coordina el momento, que el interés por fortalecer las prácticas participantes. En esta impronta unilineal de la formación, quien coordina el momento no se lleva nada. Es decir, no admite que puede haber elementos que le pueden ser útiles. $Y$ si así lo considera, no lo dirá en voz alta, pues es tomado como signo de debilidad en lugar de cooperación y aprendizaje mutuo.

- Cabe aclarar que estos denominados "hacedores de apoyo" son convocados justamente por su doble trayectoria tanto el ámbito de la práctica como de la academia, incluso algunos/as miembros de grupos o co- 
lectivos, pero que a la hora del espacio de formación, retornan a figura clásica de la formación desde el cual está quien detenta el saber y quienes más o menos pasivamente lo recibe. En el mejor de los casos entonces, "se trae un conocimiento a compartir".

- En definitiva los materiales que comparten implican en general una traslación a crítica de saberes producidos externamente a los territorios desde los cuales las prácticas son oriundas, sino que tampoco se hacen comparaciones. De hecho han convido en los encuentros, lógicas no solo diferentes, que podrían ser tomadas como una apertura, sino francamente contradictorias y aceptadas como viables indistintamente para las prácticas.

- En este sentido se ha pasado de compartir espacios de cuestionamientos fuertes, podríamos decir a los contenidos de la matriz dominante en los que aparecía un unánime acuerdo, hacia la aceptación también positiva de léxicos provenientes de academias y escuelas de formadores de gestores culturales vinculados a mercado de negocios, marketing cultural, elaboración de pac- kaging, consumos culturales, recursos humanos donde cada hacedor finalmente es un recurso en sí y no una persona con múltiples recursos, y toda una serie de terminología proveniente, no inocentemente de las ciencias económicas más clásicas que buscan hacer ingresar en la misma lógica de mercado capitalista a los "emprendedores culturales".

- Este estilo de pedagogía ahoga las creatividades; es detentadora de miedos: a que se puedan dar cuenta que "no sabe". Entonces va a los seguro y no arriesga en la búsqueda y exploración con otros. En casos extremos hasta quienes intentan hacerlo salir de su estructura tienen como respuesta el maltrato, la desacreditación y hasta cuestionarle la veracidad de las situaciones y actividades planteadas por los referentes de las prácticas: "es imposible que haya sucedido eso". Este extremo de pedagogía no solo no se acerca a la co-formación sino que se convierte en una claramente autoritaria. $Y$ las reacciones de las prácticas son el malhumor, la bronca, la sorpresa y/o abandonar el espacio. 
Matriz Subalterna

Se ha manifestado a través de:

- El deslumbramiento por las "técnicas" de presentación del convocado/a como co-formador/a: "cuánto sabe...yo nunca voy a saber todo lo que sabe" que no solo no motiva la profundización de las prácticas sino que hasta inhibe la participación en el espacio ("no pregunto porque van a creer que soy una tonta o que es una pavada lo que pregunto"). De esta manera se refuerza el "Yo no sé y el otro sí". La percepción de la lejanía entre uno y otros, genera en algunos la necesidad de dejar vacante su lugar.

- Esta domesticación que lleva a creer a algunas prácticas (por suerte las menos) a aceptar una posición en la que necesidad que les digan lo que hay que hacer, aparece finalmente como la denigración de lo propio.

- Existe asimismo una suerte de "farandulización" en la que son convertidos quienes deben coformar, conspira contra las propias prácticas. Donde la cáscara es más importante que el contenido (cómo está vestido/a, si es linda o fea/o, dónde estudió, etc.). Metáfora de la superficialidad buscada desde los medios hegemónicos de comunicación y la ba- nalización de la realidad que se hace desde el campo de la política.

- Internalizar a quien funciona (adrede o no) como operador de la opresión (el consentimiento de las víctimas que ha logrado el capitalismo), no permite ver cómo este dispositivo deshabilita aquello justamente que cuestiona lo heredado. Aquí se plantea un doble juego: 1) la epistemología del "consagrado" anula otras epistemologías posibles que estén rondando por las prácticas; 2) que la epistemología dominante ignore o desestime los aspectos epistemofílicos para que los "otros" ingresen en LA epistemología, al tiempo que se ocultan las condiciones por las cuales tampoco se pudo acceder libremente a esa epistemología que se presenta como universal y reificada, pero que ha sido impuesta (más allá de las luchas internas en el campo educativo). Incluso impuesta a los propios formadores mediante el prestigio de sus representantes e instituciones.

\section{Matriz Resistencia}

- Por un lado las manifestaciones expresiones de aquellas prácticas que tienen un amplio recorrido en su campo y en lo 
experiencial y territorial. En general sus referentes se plantan ante estilos clásicos de formación a través de: aburrimiento, bostezos, pararse, irse y volver, etc. Todas manifestaciones de la pérdida de interés, no por los contenidos si no por las formas y la modalidad. Más si cuando se hacen preguntas específicas para sus prácticas, las respuestas quedan muy alejadas o son incluso inferiores a las que ya utilizan esas prácticas. El conocimiento letrado no termina de entrar. No se devuelve.

- Por otro lado, la construcción de topías cotidianas a partir de brindarle peso al lenguaje. Esto es: "de los hacedores para los hacedores". Hacedores hace referencias a aquellos creadores, gestadores, gestionadores, productores, autores de sus propias prácticas grupales (y por ende de sus destinos) y que buscan ampliar su entramado con prácticas hermanas similares o complementarias.

- Utilizan los dineros públicos recibidos en calidad de subsidios, reconocimientos en monto estímulo, becas, comodatos, etc., a los fines de sostener $y$ profundizar sus acciones en los barrios desde los que dan cuenta de la existencia allí, aun en condiciones objetivas de exclusión y hasta de abandono total, de creatividad, de belleza. Rompen con las estigmatizaciones construidas descontextualizadamente, dan cuenta de la apertura de oportunidades, de la búsqueda de igual lo que es desigual, del derecho a la alegría, a participar de la vida comunitaria sin que necesariamente sea mediada por el comercio pero al mismo tiempo con calidad. Rompiendo construcciones míticas acerca de que la competencia es el factor necesario y suficiente para que las producciones posean calidad, sentido.

- Hacedores/as de prácticas que cuestionan las formas clásicas de intervención social en los barrios, no para descartarlas, sino para sumar nuevas dimensiones, como la cultural, al trabajo en las comunidades, sobre todo en aquellas que son vulneradas sistemática e históricamente (exponiendo sus métodos de como insertarse fundamente en un barrio, cómo generar canales reales de participación, de mostrar otros mundos posibles a quienes no les dejan más alternativa que internalizar un destino ya predeterminado). 
- Prácticas que demuestran una capacidad de gestión que superan en impacto y pertenencia a muchas de las acciones gubernamentales, aun con menor cantidad de recursos económicos.

- Hacedores/as que hacen política cultural más allá que sus criterios sean o no tomados por las políticas culturales públicas.

- En este sentido y yendo al plano de la generalización, estos hacedores que cumplen las funciones completas del pensar, el decir y el hacer concretos, se imbrican en un contexto donde prácticas que buscan la emancipación (movimientos de campesinos por la tierra, cultura viva comunitaria, movimiento de mujeres, etc.), donde aun con contradicciones van viendo las maneras de pensar culturas imaginadas posibles y las características que sus hacedores deben poseer.

- En definitiva estas prácticas se oponen al modelo "capacitador" o docente clásico, buscando encontrarse en espacios de intercambio de saberes, de pensamientos y de acciones concretas. No pierden tiempo, no son solo un ejercicio intelectual.
LA DIMENSIÓN POLÍTICA

TAMBIÉN ATRAVIESA LA

CONSTITUCIÓN DE LA

IDENTIDAD DE LOS

HACEDORES DE APOYO

Se presentan dos aspectos bien diferenciados en los que se manifiesta este atravesamiento:

1) La desmatrización de los formatos más o menos clásicos de la formación, a los fines de generar una rematrización acorde a lo demandado por la necesidad de las bases que sustentan Cultura Imaginada. Sin disociarnos de los múltiples contextos que conforman los campos que atraviesan nuestra cotidianeidad, el binomio desmatrización-rematrización nos lleva al plano de la disputa por la redefinición de reglas dentro del campo sociocultural en general (Bourdieu y Waquant, 1995), pero particularmente en la epistemología vinculada a las modalidades pedagógicas en donde persisten características de subalternidad portadas por algunos de sus hacedores. Como quedó claro, no existe homogeneidad en los criterios pedagógicos de quienes se convierten en hacedores de apoyo para la co-formación entre pares. Esto implica que se darán al menos, dos 
disputas en simultáneo: a) la definición de los criterios pedagógicos para ser hacedores de apoyo y b) entre el conjunto de estos hacedores y aquellos representantes de las formas más clásicas de pedagogías a las que podríamos llamar, de educación bancaria (Freire, 2008). Es claro que para poder disputar en el plano general, es necesario resolver las contradicciones entre aquellos que forman parte de las prácticas culturales colectivas con interés en modificar situaciones coyunturales y estructurales del campo social. En esta línea se trata de plantear criterios compartidos en función de co-formar no solo desde lo sentipensante (certeza en la educación popular) sino que al ser hacedores pares, es imprescindible apropiarse de herramientas didácticopedagógicas pertinentes para cumplir tal fin. De esta manera garantizar coherencia partiendo desde las experiencias de otros hacedores en diferentes trayectorias de sus prácticas. La disputa por la redefinición de las reglas vinculadas a las pedagogías de co-formación que regirán con mayor hegemonía el campo cultural futuro, se volcará con mayores posibi- lidades hacia los hacedores de apoyo cuanto antes definan aquello que los identifica epistemológica y pedagógicamente. Esta resignificación en el campo cultural no implica necesariamente modificaciones en las estructuras sociales. Para que esto suceda los cambios productos de las luchas al interior del campo, deberán profundizar la articulación con instituciones de los campos de la salud, lo social, lo educativo, lo económico (Bianco Dubini, 2008).

2) El poder sobre los propios actos: no vasta desarrollar una visión del poder meramente sociológica (sometedores-sometidos, opresores-oprimidos), sino plantearse modalidades de co-formación que recuperen el acto global de prácticas insertas en contextos concretos de implementación. El sentido del hacer se restituye cuando los hacedores comprenden y vivencian cómo sus actos parciales (sus contribuciones particulares) son parte de un proceso que conduce a lograr el fin pensado (Mendel, 1995). De esta manera se reconocen en los logros y resultados y también en las dificultades y "fracasos". Pero siempre pueden construir es- 
pacios de reflexión y discusiones argumentadas a los fines de plantearse alternativas que produzcan modificaciones en sus acciones. Y esto es así aún en grupos o instituciones que tienen división de tareas y distintas áreas en relación a su complejidad de estructura organizativa. La posibilidad de darle sentido a lo que se hace es político en tanto productor de salud. El movimiento de apropiación de los efectos positivos que produce el acto de trabajo no alienado (cualidad antropológica que los seres humanos poseemos), genera sensaciones de placer en la psíquis y se plasman concretamente en el campo sociocultural en la medida que se es autor (colectivo) de lo creado y protagonista de la implementación de actos con sentido.

En esta línea, las prácticas con sentido colectivizado, suponen una ruptura ideológica con el modelo capitalista opresor en sus distintas variantes, se reconocen en el proceso de trabajo del conjunto de prácticas y determinan con cuáles se va de la mano y con cuales aún no, o jamás.
PROPUESTAS PARA UNA PROFUNDIZACIÓN DE LA

\section{FIGURA DEL HACEDOR}

\section{CULTURAL DE APOYO}

En clave de utopías que superen alternativas transformadoras dentro del modelo imperante, pueden plantearse algunas acciones concretas y viables en las que se están trabajando desde Cultura Imaginada y que pueden tomarse como indicios que formarían parte de una Matriz que se había dejado pendiente de presentar: de Liberación:

- Continuar perfeccionando la figura de la co-formación, fundamentando desde una epistemología de la práctica, construyendo conocimientos sin la necesidad de divorciarlos de los conocimientos validados solo desde la academia. Para la mirada de hacedores estratégicos es clave utilizar esos saberes al servicio de prácticas que le den un sentido total y no fragmentado en categorías excluyentes.

- Visibilizar y facilitar el encuentro de prácticas es un germen de co-construcciones de saberes y haceres. Desde 2016 que se va ampliando esta posibilidad. Ya se han encontrado virtual o presencialmente 
distintas prácticas, afianzando regiones como fue Exploratoria 2018 en la región Cuyo Andino. Y para este 2019 además de la convocatoria Exploratoria 2019 de prácticas y organización de Encuentros en la Región Nordeste (Chaco, Corrientes, Formosa y Misiones) se está planteando el apoyo de entramados concretos entre 3 prácticas.

- Pensar un espacio de formación de co-formadores de apoyo: anclado en el suelo, es decir, considerando que somos seres domiciliados en el mundo (Kusch, 1976). El papel de estos hacedores es central no solo pedagógicamente sino políticamente. Son quienes a partir de sus críticas a las prácticas retomar emergentes que develen propuestas alternativas y alterativas a las imperante en el campo en el que se desenvuelven (Gagneten, Tierno y Colombo, 2017).

- Entrama 2019: frente a la idea de pocos receptores de saberes, seguir reconociendo prácticas que se conviertan en "maestras" para no solo funcionar como co-formadoras, sino con posibilidades de entramarse estratégicamente. Si bien hoy pueden ser alternativas (a lo económico productivo y las formas de hacer cultura) de su experiencia pue- den surgir otras formas de intercambio al margen del capital. Se implementará por primera por medio de la vinculación de 3 prácticas a los fines de que dos de ellas colaboren en la producción y formación de hacedores para el mejoramiento del desarrollo de la estrategia de comunicación e imágenes significativas de la tercera práctica

Tiene como finalidad fortalecer la calidad de las producciones generadas por grupos/instituciones, de la misma o de diferentes regiones del país, a partir de la realización de acciones cooperativas de apoyo recíproco (herramientas técnicas, artísticas, de gestión, etc.) y de coformación entre prácticas complementarias reconocidas por el Programa de Cultura del CFI. Asimismo esta tarea pretende aportar al desarrollo cultural de los campos específicos de actuación de estas prácticas en particular y al de sus provincias y regiones de pertenencia en general. Esta tarea supone:

- Contribuir a la sustentabilidad económica de las prácticas culturales mediante:

- la difusión de los resultados logrados y los beneficios generados mediante la pro- 
ducción colectiva; la calidad de la producción lograda y la visibilización de los aportes específicos que cada práctica de apoyo realizó, será una oportunidad para mostrar su quehacer y generar posibles contactos para futuras producciones.

- Favorecer el funcionamiento vivo de la red de prácticas.

Metodología de trabajo

- Actividades de preparación:

- Seguimiento del trabajo de grupos independientes y sus prácticas con las que se ha venido trabajando en las diferentes acciones del Programa de Cultura.

- Identificación vacancias y necesidades de las prácticas y análisis de las cualidades y especificidades de aquellas prácticas que puedan soluciones a los fines de pensar e implementar, acciones que signifiquen un salto cualitativo y/o cuantitativo en sus actividades cotidianas.

- En este sentido una práctica puede funcionar como receptora del apoyo o brindar ese apoyo a otra en función de la pertinencia de su expertiz

- Comunicación con los referentes de las prácticas a los fines de:

- actualizar información de lo que vienen realizando;

- conocer la agenda de actividades para determinar para qué acciones/eventos claves intervenir.

- Análisis de las propuestas temáticas pertinentes sobre las que trabajar y elección de las prácticas que las puedan abordar en función de sus saberes, experiencia y tiempos.

- Selección de la propuesta final de trabajo.

- Acuerdos para el trabajo colectivo.

- Se tendrá especial atención en aquellos casos que se pueda avanzar sobre acuerdos de trabajo reciproco entre prácticas, es decir, que todas las prácticas participantes den algo y reciban algo.

- Planificación entre todas las partes involucradas, de las tareas a llevar a cabo

- Estas tareas previas se podrán realizar a distancia (desde los lugares de origen de los hacedores de apoyo) aprovechando el manejo de medios digitales

- Actividades de producción:

- Serán llevadas a cabo de manera presencial (en el te- 
rritorio de las prácticas asistidas) y finalizadas (en caso que la tarea así lo requiera) en los lugares de origen de las prácticas de apoyo convocadas.

- Cultura Imaginada acompañará todo el proceso de trabajo, incluido la implementación de la producción colectiva en los eventos y acciones pautadas.

- Las grupos/instituciones asistidos podrán invitar otras prácticas territoriales que consideren pertinentes para que participen en calidad de observadores.

- Implementación:

- Posteriormente a los eventos/actividades realizados, las prácticas asistidas realizarán una devolución a Cultura Imaginada, vinculada al impacto concreto que le ha generado tanto las prácticas de apoyo, como los resultados de la implementación de los nuevos aportes.

- Lo mismo realizarán las prácticas de apoyo, una devolución a Cultura Imaginada en relación al trabajo colectivo. Para realizar esta devolución, se les proveerá de una guía con puntos clave a abordar, además de otros aspectos que la propia práctica desee incluir.
A MODO DE CIERRE: EL HACEDOR DE APOYO COMO GARANTE DE LO EMERGENTE. Los límites marcados a la institución por su dependencia formal y su carácter de apoyatura y no propositiva, hace de ella una productora de acciones, a lo sumo, alternativas. No obstante, las aristas de las propuestas que lleva a cabo Cultura Imaginada, poseen resquicios estratégicos por los que gestar las condiciones para la implementación de acciones que sean identificadas como parte de una matriz liberadora.

Las propuestas de profundización de la tarea de los Hacedores/as de Apoyo, planteadas más arriba, son la manera indirecta en que Cultura Imaginada supera los límites institucionales formales. No será protagonista en la generación de las rupturas, pero colabora en que lo alterativo surja de los métodos que las prácticas comiencen a registrar a partir de sus imbricaciones.

La sistematización de los diferentes abordajes existentes para situaciones que son similares, 
incorpora el valor de lo diverso y la creatividad como aspecto clave para seguir desarrollando la capacidad del hacer. Por estos motivos, es que la explicitación de métodos, debe ser compartida no solo por las prácticas entre sí, sino estratégicamente en los espacios de formación de las futuras generaciones de hacedores/gestores culturales.

Desmatrizar lo instituido, lo epistemológico dominante. Romper con el pensamiento heterónomo, ese que necesita de la imposición del pensamiento único para colonizar mentes, cuerpos, gustos, elecciones, consumos...

Las prácticas serán alterativas cuando los hacedores culturales lo seamos también.

\section{BIBLIOGRAFÍA}

Bianco Dubini, G. (1/2017): Cultura Imaginada. Revista Regional de Trabajo Social. (31-69). P.3-7. Montevideo. EPPAL.

(2008): Trabajo social

y autonomía cultural comunitaria. La experiencia del método-proyecto: Orígenes e Influencias en Nuestra América Latina. Buenos Aires. Espacio Editorial.

Bourdieu, Pierre y Louis Waquant (1995): Respuestas para una antropología reflexiva. México: Grijalbo.
Castoriadis, C. (1993): La Institución imaginaria de la sociedad. Buenos Aires. Tuquets.

Consejo Federal de Inversiones (2019): Cultura Imaginada Exploratoria 2018 Región Cuyo Andino: Síntesis de las prácticas colectivas seleccionadas y preseleccionadas. Buenos Aires. CFI.

Consejo Federal de Inversiones (2017): Cultura Imaginada 2017 "De los Hacedores para los hacedores". Recuperado de: http://bit.ly/Culturalmaginada-2017. Buenos Aires. CFI

Consejo Federal de Inversiones (2016): "Cultura Imaginada 2016: Síntesis de las prácticas colectivas seleccionadas y preseleccionadas". Buenos Aires. CFI.

Dejours, C. (2003): L'évaluation du travail à l'épreuve du réel. Paris. Editions Quae

(1990): En Trabajo y desgaste mental. Buenos Aires: Humanitas.

Freire, P (2008): Pedagogía de la autonomía. Siglo XXI Editores.

Gagneten, M, Tierno, P. y Colombo, G. (2017): Hacia una epistemología de la práctica. Buenos Aires. Mimeo.

Gagneten, M. (2008): "Seis matrices populares en la trama cultural. A partir de una metodología de sistematización de la práctica", Tesis de Doctorado, Facultad de Filosofía y Letras, Universidad Nacional de Buenos Aires, Mimeo.

Kusch, R. (1976): Geocultura del Hombre Americano. Buenos Aires. Editorial García Gambeiro.

Mendel, G. (1995): La sociedad no es una familia. Buenos Aires. Editorial Paidós. 